\title{
História da comunidade quilombola de Olaria (Irará/ Bahia) e a luta pela terra na contemporaneidade*
}

Jucélia Bispo dos Santos ${ }^{l}$

Faculdade Nobre de Feira de Santana

Este artigo enfatiza as trajetórias sociais dos sujeitos que habitam na comunidade quilombola de Olaria, em Irará- Bahia. Destaca-se como ocorreu a origem quilombos na organização do espaço regional, que se formou através do projeto de colonização do sertão baiano. A origem desta comunidade está associada a esse processo de resistência, que se deu especialmente no final do século XIX, quando a economia açucareira entrou em crise e os movimentos de intinerâncias de escravos aumentou na região pesquisada. Daí passou a existir uma constante circulação de uma população negra que percorria a micro-região (incluindo nesse exemplo Irará) em busca de terras para trabalhar. Também apresenta-se o atual cotidiano, o qual é demarcado pela necessidade de aquisição de bens materiais, necessários para a construção da dignidade humana, já que a história desses sujeitos é marcada por uma trajetória coletiva de sofrimento e pobreza. Também foram descritos as suas práticas culturais e suas tradições.

Palavras-chave: História - Terra Identidade - Quilombos
This article emphasizes the social trajectories of individuals living in the black community of Pottery, to anger Bahia. Stands out as the source quilombos occurred in the organization of regional space, which was formed through the colonization project of Bahia. The origin of this community is associated with this process of resistance, which occurred especially in the late nineteenth century, when the sugar economy was in crisis and the movements of intinerâncias of slaves increased in the area surveyed. It came to be a constant movement of a black population that went through the micro-region (including this example Irará) in search of land to work. It also shows the current routine, which is marked by the need to acquire material goods necessary for the construction of human dignity, since the history of these subjects is marked by a collective history of suffering and poverty. They also described their cultural practices and traditions.

Keywords: History - Land Identity - Quilombos

\footnotetext{
* The history of the quilombola community of Pottery in Irará, Bahia and the battle for earth today Mestre em Estudos Étnicos e Africanos pela Universidade Federal da Bahia, professora de Teorias Sociológicas da Faculdade Nobre de Feira de Santana. Endereço para correspondências: Faculdade Nobre de Feira de Santana, Av. Maria Quitéria, 2116, Kalilândia, Feira de Santana, BA, 44025-250 (prof.jucelia@bol.com.br)
} 


\title{
Introdução
}

\begin{abstract}
A Bahia tem um índice populacional estimado de 13.950.146 habitantes. De A acordo com os critérios cor/etnias têm-se os seguintes números: brancos, $20,9 \%$, negros $14,4 \%$, pardos $64,4 \%$, amarelos ou indígenas $0,3 \%$. O número de negros e mestiços corresponde à maioria dos que habitam esse território. A população negra habita espaços vistos como segregados, como as regiões periféricas das cidades e do campo. Por meio das produções literárias, é possível pontuar que, na Bahia, assim como em outros Estados do Brasil, no período pós-abolição, os negros foram expulsos das regiões centrais da cidade (CARRIL, 2003; p. 33). Essa questão promoveu uma divisão territorial dos espaços urbanos e rurais que foi definindo uma territorialidade, em que os grupos "de cor" foram se estabelecendo em lugares segregados, como as comunidades quilombolas.
\end{abstract}

As temáticas de pesquisa que têm os remanescentes de quilombos como eixo de discussão receberam uma atenção especial nos últimos anos. Depois da Constituição de 1988, os quilombolas passaram a ser vistos como sujeitos de direitos, sobretudo no que diz respeito ao direito à titulação e tomada de posse de suas terras. $\mathrm{O}$ artigo 68 do Ato das Disposições Constitucionais Transitórias da Constituição Federal de 1988, da seção dos Atos e Disposições Transitórias, fala sobre a concessão dos títulos de propriedade aos remanescentes de quilombos. Tal discussão tem sua origem na crescente organização dos trabalhadores do campo e na ascensão do movimento negro, enquanto movimento político que afirma a identidade étnica inserida no conjunto das lutas dos trabalhadores pela posse da terra. Nessa vigência, nascem novas pesquisas e novas esperanças de conquistas de direitos, para as pessoas que residem nesses espaços.

Para tanto, este artigo almeja trazer a discussão dos direitos dos quilombolas da comunidade da Olaria, em Irará-Bahia, porque, apesar de existirem comunidades que já foram recenseadas pela Fundação Palmares, nenhuma ainda foi reconhecida. O resultado desta pesquisa poderá contribuir para a afirmação de identidade étnica, que se vincula às perspectivas de organizar sua divulgação aos moradores dessas localidades, enquanto descendentes de escravos fugidos, mas na possibilidade de se atuar politicamente a partir de sua demarcação espacial e do reconhecimento social de sua memória e identidade. Além disso, este projeto busca gerar as bases de uma sistemática para acompanhamento das informações que identificam as comunidades negras rurais.

Vale ressaltar que as comunidades quilombolas não ganharam plenas condições de cidadania a partir da Lei Áurea. Na verdade, muitos negros tiveram sua cidadania obscurecida por vários anos. Esta lei de "suposta" liberdade para escravos não garantiu o direito às mínimas condições de que estes sujeitos necessitam para sobreviver, como: terras, moradia descente, água encanada, sistema de esgoto, educação, dentre outros. 
A realização desta pesquisa tornou-se relevante por diferentes motivos: atualmente fala-se de quilombos como uma designação jurídico-constitucional para delimitação do território quilombola; que o número real de quilombos na Bahia é muito maior do que é registrado; os nativos das comunidades quilombolas precisam conhecer o sentido jurídico e político da identidade quilombola para assegurarem os direitos às políticas sociais que são destinadas para os cidadãos que residem nestes grupos. O primeiro passo do reconhecimento de uma comunidade quilombola parte do processo de conscientização da população. Portanto, este projeto pretende criar estratégias que auxiliam aos remanescentes de quilombos a se conscientizarem e a conhecerem as leis que funcionam a seu favor. Vale destacar que, para uma comunidade ser reconhecida como sendo quilombola, qualquer integrante da mesma pode enviar um ofício para a Fundação Palmares solicitando a presença de uma equipe no local da comunidade, para registrar seus dados populacionais e territoriais. Depois fazse um Relatório Técnico de Identificação e Delimitação da comunidade para ser publicado em Diário Oficial. Após esse período, a comunidade é reconhecida como sendo quilombola, com direito à propriedade da terra que historicamente lhe pertence. Delimitado o território, o grupo terá direito a sua terra. Portanto, esta investigação ganha proeminência não só pelo fato de falar de remanescentes de quilombos e identidades, questões em evidência hoje no meio acadêmico, mas também pelo fato de tratar de um tema pouco pesquisado no referido espaço delimitado. Os temas sobre escravidão na Bahia possuem pouca investigação na região do Sertão baiano. Até então, estão silenciados nas investigações científicas que, em sua maioria, tratam da região do Recôncavo baiano.

\section{Revisão do conceito de quilombo}

A historiografia clássica dos quilombos, que foi utilizada no Brasil por alguns intelectuais, foi responsável pela construção da idéia de quilombos como um local isolado, formado por escravos negros fugidos. Nesse exemplo, surge logo a reflexão do Quilombo de Palmares, com seu herói Zumbi. Essa noção de quilombos que foi construída pela história oficial, ainda permanece enraizada no senso comum (CARVALHO, 1996; pp. 7-10).

Uma nova perspectiva da historiográfica dos quilombos ganhou ênfase, no Brasil, em meados dos anos 70, especialmente através das contribuições de Artur Ramos (1953) e Edson Carneiro (1958). Esses autores atribuíam, excepcionalmente, a origem dos quilombos a um histórico passado, cristalizando sua essência, no período em que vigorou a escravidão, no Brasil. Dessa forma, os quilombos eram exclusivamente caracterizados como expressão da negação do sistema escravista. Ou seja, a formação de quilombos era vista como um fato estabelecido no passado, bem distante do tempo distante. 
O conceito clássico de quilombos foi fundamentado através de análises que se prendiam, exclusivamente no perfil das fugas dos negros escravos e na posterior organização desses sujeitos. O quilombo advinha da resistência à exploração, na qual o negro africano criava constantes atos de rebeldia, desde tentativas de assassinato de feitores e senhores até fugas e, mesmo, suicídio. O escravizado via no quilombo a perspectiva de ter uma vida em liberdade, longe das punições e das regras estipuladas pela escravidão:

Um quilombo é um esconderijo de escravos fugidos. É preciso distingui-lo dos verdadeiros movimentos insurrecionais organizados contra o poder branco. O quilombo quer paz, somente recorre à violência se atacado, se descoberto pela polícia ou pelo exército que tentam destruí-lo, ou se isto for indispensável à sua sobrevivência. Quilombos e mocambos são constantes na paisagem brasileira desde o século XVI. Reação contra o sistema escravista? Retorno à prática da vida africana ao largo da dominação dos senhores? Protesto contra as condições impostas aos escravos, mais do que contra o próprio sistema, espaço livre para a celebração religiosa? Os quilombos são tudo isso ao mesmo tempo (MATOSO, 1990; pp. 158-59).

Essa noção de quilombos traz uma significação presa ao passado remoto da história, ligado exclusivamente ao período no qual houve escravidão no Brasil. Nessa perspectiva teórica, o quilombo era exclusivamente formado através da rebelião contra esse sistema colonial escravista. Ou seja, após as fugas, os negros iam se esconder e se isolar do restante da população nos lugares mais remotos da colônia. Os ex-escravos formavam agrupamentos que recebiam nomes variados, conforme as específicas regiões do Novo Mundo: quilombos ou mocambos no Brasil; palenques na Colômbia e em Cuba; cumbes, na Venezuela; marrons no Haiti e nas demais ilhas do Caribe fran-cês; grupos ou comunidades de cimarrones, em diversas partes da América Espanhola; maroons, na Jamaica, no Suriname e no sul dos Estados Unidos (MIRADOR, 1980; p. 156).

No Brasil, a partir dos anos 70 do século XX, sobreveio uma preocupação acentuada em torno da discussão da identidade das comunidades negras rurais. Esses debates formam travados especialmente pelos antropólogos e militantes dos movimentos sociais, com ênfase maior do movimento negro. Esta luta proclamava a reivindicação por uma reparação da incomensurável dívida do Estado brasileiro para com a população negra, 


\section{História da comunidade quilombola de Olaria (Irará/Bahia)...}

que sofre a dupla opressão enquanto camponesa e parte de um grupo racial inserido numa sociedade pluriétnica, mas desigual. Por conta desses debates, foram promovidas novas perceptivas em torno da conceituação de quilombos que associam à idéia de quilombos a formação dos grupos dos descendentes que escravos que vivem durante o Brasil Colonial e nos períodos posteriores. Com isso, aparece a argumentação que considera o quilombo como um processo de resistência permanente por parte dos sujeitos, que vivem nessas comunidades. $O$ conceito de resistência se ampara no âmbito da resistência cultural. Dessa forma, a categoria quilombos se configura na esfera da segregação social dos povos que descenderam dos antigos escravos, que experimentaram a vida no cativeiro.

Contemporaneamente, foram elaboradas novas interpretações sobre a história dos quilombos no Brasil. Os estudos recentes se empenham em entender a complexa rede estabelecida entre os quilombolas e os diversos grupos da sociedade com quem os fugitivos mantinham relações (CARVALHO, 1996; pp. 7-10). Essas novas discussões apontam que os quilombos mantiveram relações com a sociedade ao seu redor, ou seja, a mesma sociedade que os dominou muitas vezes, manteve contatos com quilombolas em troca de benefício econômico. Os autores João José Reis e Flávio José Gomes (1996) mostram como um quilombo podia manter relações de sociabilidades com "outros" sujeitos que viviam ao redor das comunidades quilombolas. Eles "exemplificam essa consideração, através das análises, como as que foram desenvolvidas em torno da história dos coiteiros no quilombo do Oitizeiro Bahia, 1806". João Reis problematiza a perspectiva historiográfica que consideravam que escravos fugidos viviam escondidos, estabelecendo apenas relações divergentes com os moradores livres. Na rediscussão do conceito de quilombos, Flávio dos Santos Gomes apresenta a idéia de "campo negro". Essa relação destaca como os negros viviam "uma complexa rede social permeada por aspectos multifacetados que envolveram, em determinadas regiões do Brasil, inúmeros movimentos sociais e práticas econômicas com interesses diversos". Essas são algumas, das várias investigações que revêem o conceito clássico(GOMES, 1996; pp.30-45).

Os agrupamentos, que são vistos pelas abordagens atuais, recebem diferentes nomenclaturas, como: terras de preto, território negro e comunidades de quilombos. Contudo, todas essas denominações são utilizadas por vários autores para enfatizar a categoria de quilombo como uma "coletividade camponesa", definida pelo compartilhamento de um território e de uma identidade (ANJOS, 2005; p. 92). Presentemente, a identidade quilombola vem sendo discutida no Brasil a partir da necessidade de lutar pela terra. A consciência em torno da identidade quilombola constitui o critério fundamental para o reconhecimento de uma comunidade remanescente de quilombo. 
Assim sendo, o processo de conscientização da identidade quilombola tornouse um critério essencial na luta pelo reconhecimento das comunidades, enquanto remanescentes de quilombos.

\section{Considerações metodológicas}

Este trabalho foi desenvolvido a partir da perspectiva historiográfica da História imediata, a qual visa recuperar as marcas significativas do passado a partir de depoimentos orais, enquanto fonte para a sua produção (MONTENEGRO, 1994; p. 15). A partir deste conceito, far-se-á uma leitura de história que busca na interdisciplinaridade um arcabouço para a sua sustentação. Neste caso será feita uma aproximação com a Sociologia e com a Antropologia.

A compreensão de memória investigada está baseada na idéia de memória de Eclea Bosi (1993), que estabelece uma compreensão do conceito de memória pessoal enquanto condição de uma visão social, familiar e grupal. Este exemplo teórico metodológico pode ser descrito como uma compreensão da oralidade que se busca a partir dos esquemas operatórios dos sujeitos envolvidos na pesquisa, com uma leitura da oralidade baseando-se em pressupostos de caráter introspectivo. A memória é destacada como um fato social, sendo que as lembranças do passado são observadas como objetos de rememorização de alguns registros. Além da utilização da memória oral, será utilizada também a idéia de memória enquanto monumento, que é destacada por Le Goff(1990). Esse conceito é baseado no princípio da memória que pode estar materializada em imagens do passado, na condição de fotografias de objetos pessoais presentes no cotidiano. Desta maneira, os utensílios dos quilombolas (potes de cerâmica, esteiras de palha, fogão de lenha, peneiras, ferramentas de trabalho, etc.) apresentam pistas de seu passado, assim como quaisquer espécies de fotografia, serão utilizados enquanto mecanismos de investigação deste tema.

Outro modo de cercar os objetivos destacados será através de entrevistas, partindo do conceito de memória citado anteriormente. Nessa perspectiva o método de entrevistas abre-se para a possibilidade de se estudar o passado vivido, o que mantém uma relação com as experiências do presente (BENJAMIN, 1994; pp. 197-223). Os sujeitos que habitam nesta localidade guardam em sua memória elementos que, talvez, não tenham sido registrados. A princípio, pode-se destacar que as principais dificuldades encontradas para traçar este tema se processam no fato destes sujeitos se valerem pouco de registros escritos em seu cotidiano, pois se trata de comunidades que possuem um índice elevado de analfabetismo. Os elementos registrados na memória serão fundamentais para se buscar algumas informações que, muitas vezes, 
não são evidenciados na escrita, pois a formalidade do documento escrito não destaca as subjetividades de determinados discursos. As entrelinhas dos discursos orais apontam assuntos que, muitas vezes, são ocultados na documentação oficial, pois "os documentos socialmente escritos podem assumir uma postura política de classe que podem ser reprimida quando desagrada às autoridades. Sendo estas comunidades de perfis parecidos na construção de sua história, a busca pela questão das identidades torna-se um espaço plural de vivências sociais" (BENJAMIN, 1994; pp. 197-223).Desta maneira, torna-se então pertinente analisar como determinadas posturas foram construídas em meio a conflitos.

O modelo teórico escolhido trará uma possibilidade de leitura historiográfica a partir dos conceitos da História da Cultura, baseados em E. Palmer Thompson, que considera "o processo de luta como uma ação que desenvolve a identidade social das classes populares, e não pela difusão dogmática de qualquer doutrina" (VAINFAS, 1997; p. 100). Essa idéia servirá para discutir como os sujeitos em destaque construíram em seu cotidiano representações que lhes identificam enquanto tais. Para Thompson, o conceito de cultura e de experiência marca a leitura de uma perspectiva dos estudos que tratam de grupos sociais específicos. Com esse olhar, será trabalhada "a idéia de microhistória que discutirá o espaço social delimitado, e a prática social específica dos determinados sujeitos e a compreensão que esses desencadearam na formação de sua identidade" étnica (BARROS, 2004; p. 56).

Para Thompson, "entre as relações econômicas, havia a existência humana que constrói na sua dinâmica social em meio à política, religião, rituais, conspirações, baladas, pregações milenaristas, ameaças anônimas, cartas, hinos metodistas, festivais, danças," dentre outros (THOMPSON, 1981; p. 29). O entendimento da pesquisa histórica como parte de um projeto político vem sofrendo muitas transformações, e aproximam-se os campos temáticos mais tradicionais da história, os quais têm sido substituídos por estudos culturais, eleitos a partir de discursos privilegiados de seus acadêmicos, de "esquerda" ou não. Esse quadro se associa, direta ou indiretamente, à assim chamada "condição pós-moderna" (incluídas aí as linhas pós-estruturalistas e neopragmatistas), com sua rejeição às grandes narrativas, sua compreensão da realidade como fragmentos desconexos, sua redução da história a um conjunto de estilos de narrativa e seu efeito desintegrador sobre o sujeito - "condição" que também tem se revelado conveniente "habitat" para tendências intelectuais neoconservadoras. A interpretação que Thompson faz do materialismo histórico afirma três categorias básicas: a luta de classe como protesto, a experiência da classe trabalhadora e a idéia de moral. Thompson, crítico rigoroso quanto à validade das teorias que questionava, envolveu-se em duras polêmicas no mundo acadêmico. A obra thompsoniana reafirma alguns pressupostos do socialismo, 
mediante sua avaliação das aspirações da classe trabalhadora, definidas como defesa de sua humanidade e de um projeto coletivo. Essa abordagem priorizava a noção de "humano" na sociedade, compreendida como um movimento histórico relacionado a um ideal democrático. Na sua proposta metodológica, Thompson, dá voz às experiências individuais em forma de narrativa, modelo que busca uma compreensão mais subjetiva de documentos históricos. Ao buscar os conhecimentos dos sujeitos sociais em destaque, pretende-se narrar como essas pessoas construíram suas considerações culturais na vivência social específica.

A partir dos referenciais citados e dos devidos conceitos teóricos explicitados foram cercados os principais objetivos desta pesquisa, que tem como proposta analisar como os quilombolas do território de identidade do Portal do Sertão estão discutindo os direitos conferidos aos remanescentes de quilombos, os quais estão presentes na Constituição Brasileira de 1988.

\section{A origem da comunidade quilombola da Olaria em Irará, Bahia}

A origem das comunidades de quilombos de Irará está relacionada à estrutura social que emergiu a partir da colonização do sertão baiano. A sociedade local foi organizada, conforme um padrão de poder que se estabeleceu através da hierarquização de funções e da apropriação de recursos materiais. Os sujeitos brancos foram privilegiados na aquisição das riquezas e do poder. Estas relações estavam diretamente vinculadas ao acesso à terra, tendo sido a concentração desta o principal fator responsável pela centralização dos projetos políticos. Assim, foram estruturando as sesmarias, os aldeamentos, as freguesias, as fazendas, os currais e as vilas. Resistindo a essa ordem pré-estabelecida, os sujeitos racializados ocupavam terras formando uma estrutura fundiária que se fundamentou nas relações comunitárias, típicas das comunidades de quilombos.

Os colonizadores tomavam posses de grandes quantidades de terras e de escravos. Consequientemente, eram distinguidos como pessoas que possuíam teias de relacionamentos, através de status (WEBER, 1982; pp. 211-28). De um lado, existiam grandes proprietários de terra e escravos, autoridades provinciais e comerciantes. No grupo intermediário, existiam vaqueiros, artesãos, lavradores e pequenos fazendeiros. Na base da pirâmide social, numa total condição de pobreza estavam os mulatos, sertanejos, índios e negros sem direito à cidadania e ao acesso a terra, dominada e explorada pelas oligarquias locais que ascenderam ao poder político com a proclamação da independência. A partir desse processo, alguns sujeitos que foram desprovidos da posse da terra, ou que tiveram suas terras roubadas viviam em comunidade de quilombos. 
A comunidade de quilombo da Olaria, lócus desse estudo, é um desses espaços baianos, habitado majoritariamente, por pessoas negras. Esse fator étnico racial sempre chamou a atenção, dos outros habitantes do município. Por conta desse aspecto, no contexto regional, essas pessoas são vistas como excêntricas. Entretanto, atualmente, algo mudou no processo de identificação dessas pessoas. Nos finais dos anos 90 do século XX, a Fundação Palmares ${ }^{2}$ identificou, por meio de um censo, os antigos sítios de comunidade quilombolas do Brasil. Assim, pontuou-se que no município de Irará existem comunidades remanescentes de quilombo (ANJOS, 1999; p. 98).

A catalogação da Palmares foi executada para atender as expectativas da Constituição de 1988 no Art. 68 do Ato das Disposições Transitórias diz o seguinte ${ }^{3}$ : "Aos remanescentes das comunidades dos quilombos que estejam ocupando suas terras é reconhecida à propriedade definitiva, devendo o estado emitir-lhes os títulos respectivos". A identificação das comunidades de Irará está relacionada com um movimento que se fez presente no cenário internacional e nacional e que manifestam de maneira enfática os enfoques teóricos, ideológicos e mesmo militante de intelectuais e de organizações na defesa da etnicidade como um valor em si mesmo. (POUTIGNAT, 1997; p. 56). A consolidação desse direito acendeu um entusiasmado debate sobre o conceito de quilombo e de remanescente de quilombo. O reconhecimento de uma comunidade remanescente de quilombos define quem tem o direito à propriedade da terra.

O uso comum da terra é caracterizado através da ocupação do espaço que tem por base os laços de parentesco e de vizinhança, assentados em relações de solidariedade e de reciprocidade (ARRUTI, 2006; p. 78). Dessa forma, as comunidades de quilombos podem ser vistas como grupos minoritários que valorizam acentuadamente seus traços culturais diacríticos e suas relações coletivas, a fim de ajustar-se às pressões sofridas. Nesta perspectiva os indivíduos constroem identidades que estão relacionadas em conexão com a terra, enquanto um território impregnado de significações relacionadas à resistência cultural.

O recente conceito de quilombos que é desenvolvido no Brasil, sobretudo, nos estudos antropológicos, discorre sobre a luta política em torno das reivindicações das comunidades que se inserem no perfil de remanescente de quilombo.

\footnotetext{
${ }^{2}$ A Fundação Cultural Palmares é uma entidade pública vinculada ao Ministério da Cultura, que formula e implanta políticas públicas com o objetivo de potencializar a participação da população negra brasileira no processo de desenvolvimento, a partir de sua história e cultura.

${ }^{3}$ O Direito Étnico, consagrado pelo art. 68 do Ato das Disposições Constitucionais Transitórias, combinado com os artigos 215 e 216 da Carta Máxima busca, não apenas, promover políticas públicas afirmativas, como também, preservar a cultura tradicional dos grupos formadores da sociedade brasileira, em suas várias formas de expressão e modos de viver, tombando, inclusive, documentos e sítios detentores de suas reminiscências hisṭoricas.
} 
Essa causa tem movido diversos movimentos sociais, no campo, que se baseiam na seguridade do direito da terra determinado através da constituição de 1988. Ao tomar como base a vigência da lei estabelecida constitucionalmente e novas discussões teóricas dos quilombos, a Fundação Palmares catalogou e reconheceu diversas comunidades no Brasil. ${ }^{4}$

$\mathrm{Na}$ legislação brasileira atual, o conceito de comunidade quilombola é estabelecido através critério do auto-reconhecimento coletivo. Esta condição foi estabelecida, na legislação federal em novembro de 2003, através do Decreto $\mathrm{n}^{\circ}$ 4.887. Depois da criação deste artigo, o conceito de quilombos do Brasil entrou na pauta de um projeto intelectual tenso e contraditório, uma vez que este pode está a serviço dos interesses dominantes, mas para outros ele renasce com uma expressão teórica de movimentos revolucionários.

As elites fundiárias brasileiras tem se apropriado do conceito clássico de quilombos, o qual raciocina a origem desses grupos pressa ao passado da escravidão, a fim de negar a luta das atuais comunidades quilombolas. Para os senhores de terras, é muito mais interessante pensar que as atuais comunidades negras rurais, surgiram pela "ordem natural da divisão espacial". Dessa forma, o conceito de quilombos clássicos frequientemente é reivindicado pelos grandes proprietários fundiários, a fim de neutralizar os recentes movimentos sociais que são organizados em prol da causa dos quilombolas. Vale salientar, que o conceito de quilombo não é uma categoria construída indiferentemente aos projetos políticos. Pois, este é uma demarcação da condição de ser quilombola, sempre esteve associada às expectativas de ideologias políticas de épocas.

No Sertão baiano, o projeto de dominação colonial estabeleceu prioridades econômicas e definiu valores, conceitos e comportamentos individuais e sociais. No topo dessa sociedade estavam os homens brancos com poderes políticos e econômicos. Abaixo, aparecia uma camada média formada por pessoas livres (feitores,capatazes, padres, militares, comerciantes e artesãos) e funcionários públicos. Deste modo, passou a existir à divisão administrativa da colônia em: capitanias '! comarcas '! termos e continha, na seqüência uma subdivisão eclesiástica, que eram as freguesias (FAORO, 2000 vol.1 Cap. 1 e 3, p. 3-34 e p. 83-109). A partir dos cargos e das funções que as pessoas desenvolviam as relações de status e as redes de relacionamentos. Essa estratificação social arquitetou a sociedade de Irará, entre os séculos: XVII e XVIII.

Nas relações sociais desenvolvidas, durante a colonização, a metrópole colonizadora solidificou, ao longo dos séculos, uma rede formada por: fidalgos, clero, elite mercantil, entre outros. Esta hierarquização social surgiu em Irará, a partir do século XVII, quando os europeus avançaram os sertões adentro em busca de riquezas e poderes.

${ }^{4}$ BRASIL. Constituição da Republica Federativa do Brasil. Brasília: Senado, 1988. 
E na base da sociedade estavam os indígenas e os escravos de origem africana, que eram tratados como simples mercadorias. Esses últimos eram responsáveis por quase todo trabalho desenvolvido na colônia. Assim, as pessoas foram assumindo colocações que legitimavam o poder local:
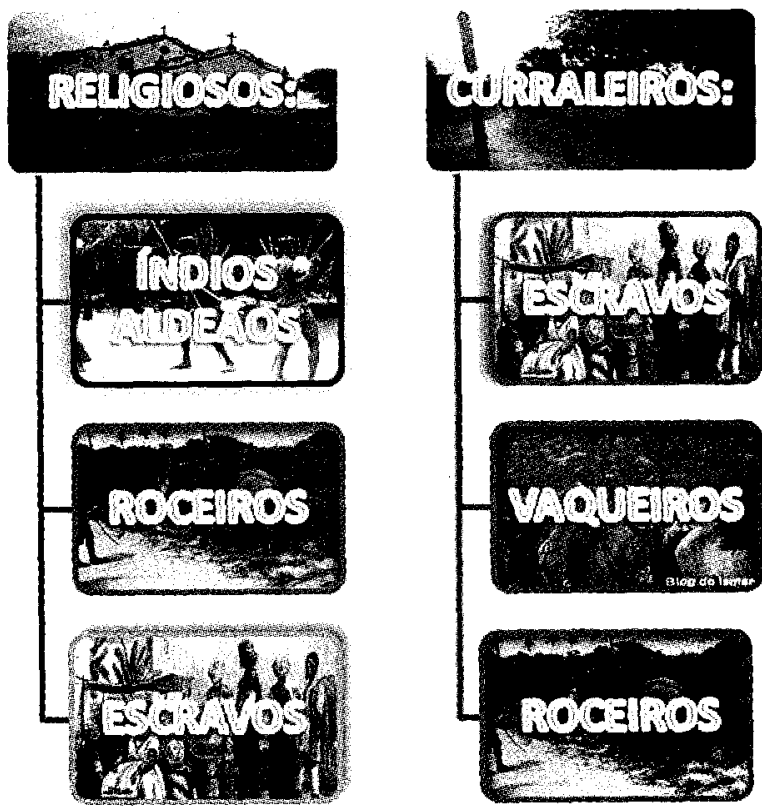

Figura 1

Relações de dependência promovidas, no Sertão da Bahia, em decorrência do projeto da colonização.

Assim, os espaços de poder foram demarcando a condição de superioridade dos sujeitos brancos, ao mesmo tempo em que também se foi criando a impossibilidade de os ditos inferiores (índios e negros) se inserirem no mundo civilizado. De acordo com Faoro, no Brasil colonial, a propriedade individual era concedida pelo Estado, caracterizando uma "sobrepropriedade" da coroa sobre seus súditos e também este Estado sendo regido por um soberano e seus funcionários. De tal modo, o modelo da colonização determinou quem era senhor, quem era escravo, quem era trabalhador explorado e também quem era "livre", estruturando, assim, relações de status."

No processo de colonização, as elites brancas tomaram posse de grande parte dos recursos materiais, excluindo e inferiorizando outros sujeitos da aquisição de bens necessários para a garantia do mínimo de dignidade,

${ }^{5}$ STATUS: nichos e posições socialmente definidos (fazendeiro, padre, vaqueiro, comerciante). 
especialmente aos sujeitos de cor. Essa ação reflete-se na questão que Pierre Bourdieu (1980) aponta como resultado de um processo de visualização e demarcação do espaço frente ao Estado ou a qualquer outro agente político, o que implica uma negociação e no conflito em torno do poder de legitimação e distribuição de recursos.

Os titulares de terras no período da colonização, ora estavam ligados à Coroa, na condição de sesmeiros, ora estavam ligados a Igreja. Percebendo a Coroa a impossibilidade de sozinha enfrentar os perigos externos e internos que ameaçavam a colonização, buscou a aliança dos senhores de terra através da criação das ordenanças ${ }^{6}$. A patente das ordenanças não era remunerada, mas conferia prestígio ao portador, fortalecendo o poder. Consolidavam-se o coronelismo e suas implicações que caracterizariam a vida sócio-politíca brasileira. Todas as terras da colônia pertenciam ou aos religiosos (jesuítas e franciscanos), ou aos criadores de gado, os curraleiros e militares. Estes personagens articularam o projeto da exploração colonial porque tinham interesses econômicos. Dessa forma, a sociedade se fundamentou no poderio dos novos proprietários rurais, geralmente ligados à pecuária, influenciando a vida político-administrativa da capitania. Historicamente, isso significou uma nova maneira de legitimar as já antigas idéias e práticas de relação de superioridade entre dominantes e dominados, como os povos nativos.

Entre os séculos XVII e XVIII ocorreram os deslocamentos da criação de gado do litoral para o interior. Esta ação nasceu graças às pressões exercidas em torno da organização da colônia como um todo. O governador Tomé de Souza propôs a separação das duas maiores atividades econômicas da colônia: "a produção da cana de açúcar e a pecuária. Assim, ele proibida a criação de gado a menos de 10 léguas do litoral, em 1701" (ABREU, 1930; pp. 120-30).

A Zona da Mata foi destinada ao plantio da cana-de-açúcar e ao Sertão ficou reservado à pecuária. Depois desse ajuste, o gado foi deslocado para regiões interioranas, distantes daquelas destinadas ao cultivo da cana. Devido a isto, os colonizadores foram em busca da conquista das terras do sertão. Terras estas que já eram ocupadas por muitas tribos indígenas, dentre elas os Paiaiás, muito comuns na região de Irará.

Com a expansão da pecuária, "a colonização seguiu Sertão adentro em busca de terras para a instalação de currais de gado" (ABREU, 1930; pp. 120-30). Deste modo, novas entradas foram abertas. A cidade de Cachoeira era o início de vários caminhos, pois o gado era desembarcado em seu porto.

\footnotetext{
"A palavra vem do latim, de ordo(inis), relativa a ordinari, "ordenar". Daí, é que se deriva a palavra ordinans(antis), "ordenança", significando "uma regra autoritária, um decreto, uma lei, um rito religioso, uma disposição ou posição, um desígnio". Enciclopédia de Bỉblia, teologia e filosofia. São Paulo, Candeia, 1995.
} 


\section{História da comunidade quilombola de Olaria (Irará/Bahia)...}

Subindo a estrada de Cachoeira, primeiro se chegava à Santana dos Olhos D’Água, atual Feira de Santana, onde se estabelecia uma divisão em dois caminhos. Um dos caminhos seguia por Santana do Camisão (Ipirá), Mundo Novo e Jacobina, tornando a dividir-se. A partir de Jacobina, um dos caminhos ia para Remanso e interior do Piauí, e o outro seguia para Juazeiro e interior de Pernambuco.

Depois que a pecuária passou a ser especificamente desenvolvida no Sertão, foram concedidas sesmarias para impulsionar a criação de gado. As sesmarias eram terras com extensões de até quatro léguas. Essas foram doadas para homens brancos, especialmente os de origem européia. Das primitivas sesmarias foram aos poucos aparecendo roças, engenhos, currais e moradas. Lentamente, as terras foram ocupadas e as pessoas se radicando ali, dedicando-se à pecuária e à agricultura.

No processo de aquisição das terras, "o sesmeiro assinava um acordo com a Coroa Portuguesa, que legitimava direitos e deveres, os quais determinavam o perfil da ocupação do território conquistado" (PORTO, 1985; p. 69). Neste processo, o outorgado, quando aceitava a concessão de terras, assumia uma série de condições que lhe eram impostas, a quais the obrigavam a pagar uma pensão anual ao proprietário do domínio direto, razão pela qual se transformava em foreiro do último. Não cumprindo o foreiro as condições do contrato, o domínio útil se reverte ao detentor do domínio direto.

Com o passar dos anos, "Guedes de Brito haviam deixado de promover a utilização de grandes áreas de seus domínios, bem como vários outros sesmeiros brindados com largas porções de terras nos dois primeiros séculos de colonização, os quais sequer haviam chegado a tocar o solo de suas propriedades" (NEVES, 1998; p. 58). Conforme Erivaldo Fagundes Neves (1998) a família Guedes de Brito possuía uma imensa propriedade de terra que fora concedida pela coroa, e mais extensões territoriais conseguidas à força e por dominação servil. Por decorrência desse processo, a propriedade formou o morgado da família Guedes de Brito, o qual fora instituído por testamento no século XVII por Antonio de Brito Correa e sua esposa Maria Guedes sendo transmitido ao seu herdeiro Antonio Guedes de Brito.

Nos anos de 1615, 1619 e 1655, o comércio do gado teve expansão na Bahia. Os comerciantes e curraleiros procuraram as melhores vias para a sua locomoção. Neste contexto, João Lobo Mesquita recebeu por cessão do proprietário da sesmaria "Casa da Ponte" uma grande área de terras, povoando-a com gado, escravos e moradias, abrindo a "estrada de boiadas" para o sertão. Em 1650, João Lobo de Mesquita concedeu parte de suas terras situadas entre Jacuípe e Água Fria a João Peixoto Viegas. Essa região abrangia, dentre outros o município de Irará.

Na carta de concessão da sesmaria que foi doada a João Peixoto Veigas, evidenciam-se se detalhes sobre os compromissos entre as partes: sesmeiro e doador. Também aparecem aspectos a respeito das propriedades, tais como: 
os limites geográficos, a fertilidade das terras, se estão na região de caatinga, se são habitadas por brancos ou por gentios (índios da tribo paiaiá), como também cita as riquezas naturais presentes nessas terras, a exemplo de rios?:

João Peixoto Viegas Senhor Possuidor das terras da Agoa Fria Itapororocas Jacuipe Velho que hummas e outras São hereos vizinhas dos Tocos [...] vizinhas das dos Tocos e Pinda em Razão de não Sabermos aonde fin 25 da alias Sabermos aonde Chegão e acabão entre nos as ditas terras temos duvida parecendo a cada qual que nos entrarmos e tomamos hum ao outro. Viemos a Com cordarmo nos e acordamos amigavelmente por Conservarmos nossa antiga e boa amizade e evitar o trabalho e gasto de demarca das entre nos e nossos herdeiros conviemos e acordamos que a prezente digo que a partir e Sorte das Terras dos Tocoz e Pinda se me fez a primeiro Seguindo a data 15 della pela forma que se diz e se marca a Provizão da Sua Sesmaria e Se ponhão marcas e Signais que Serão para Sempre de divizão com 20 as terras de Agua fria Itapororocas e Rio Jacuipe velho que tem a Sismaria de mim João Peixoto Viegas porquanto as ditas 25 terras de Tocoz e Pinda ficão ao Norte do dito Rio e Itapororocas Agua Fria [...]

De acordo com esse documento, nota-se que João Peixoto Veigas recebeu a sua sesmaria, a qual era composta pelas seguintes localidades: Água Fria (ao qual o município de Irará estava inserido na época), Itapororocas (Feira de Santana e Jacuípe (abrange toda a micro-região de Feira de Santana). Essa concessão de terras tinha como finalidade, a implantação do povoamento de vastas regiões, nas quais viviam populações indígenas e cujas terras eram ameaçadas constantemente por invasores estrangeiros, no caso, os holandeses. Essas terras foram destinadas, muitas vezes, a homens cuja principal fonte de renda viria da exploração de suas fazendas e da produção sertaneja como um todo, fosse com a comercialização do gado ou com a arrematação de cobrança dos dízimos.

\footnotetext{
${ }^{7}$ BIBLIOTECA NACIONAL (BRASIL). Documentos históricos [Tombo das Cartas de Sesmarias do Rio de Janeiro dadas por Cristóvão de Barros (1573-74) dadas por Salvador Correia de Sá (157879)] / Biblioteca Nacional. Vol. 1. Rio de Janeiro: Fundação Biblioteca Nacional, Dep. Nacional do Livro, 1928.
} 
A carta de concessão de sesmarias de 03 de julho de 1655 faz referências aos perigos da região promovidos pela luta com os indígenas. Nessa mensagem destaca-se a ameaça de assaltos e morte de escravos no confronto com os indígenas ${ }^{8}$. É possvel observar nas entrelinhas dessas informaçõè que os donos dos currais não respeitavam as terras dos antigos habitantes da região, uma vez que podiam deixar o boi solto, e este acabava por invadir o espaço natural do nativo. Logo, o homem branco invadia o espaço cultural dos indígenas. Essa dupla ação deu origem a muitos conflitos entre portugueses e indígenas. Quando os nativos atacavam o gado, os vaqueiros reagiam e o conflito muitas vezes terminava desfavorável para os antigos donos do Sertão. Por conta desse fator, nos séculos XVI e XVII, as regiões do Sertão da Bahia foram palcos de grandes conflitos envolvendo índios e brancos colonizadores. ${ }^{9}$

\section{Formação dos quilombos no sertão da Bahia no século XIX}

Nos finais da escravidão, os fazendeiros do sertão passaram a substituir a mão -de- obra escrava pelo trabalho à meia. Tendo havido grande mobilidade da população dentro do território, foi possível se estabelecer um novo reordenamento do trabalho. O crescente aumento de mão -de -obra livre na segunda metade do século XIX, com a diminuição do número de escravos, estabeleceu, ao longo do tempo, medidas de coerção e imposição do trabalho ao homem livre.

Muitos fazendeiros com pouca mão-de-obra para a produção agrícola recorriam à força de trabalhadores livres que desenvolviam suas atividades em grupos estabelecidos pela origem familiar (FRAGA, 2006; p. 25). Nesse processo, surgia a doação de terras para ex-escravos. Assim, os proprietários disponibilizavam um pequeno pedaço de terra e uma pequena casa em troca de um aluguel, e exigiam lealdade e submissão por parte dos trabalhadores, "moradores". Desse modo, o apoio ao processo lento e gradual de extinção da escravatura levou a incorporação do trabalho livre.

Os trabalhadores residentes em terras alheias continuariam tendo uma série de obrigações para com os proprietários, como por exemplo, a de prestarem certo número de dias de trabalho por semana por um preço bem baixo. Nos demais dias eles poderiam cultivar gêneros alimentícios, o que realizam com a ajuda de toda a família. Este serviço foi conhecido como o trabalho à meia ${ }^{10}$ :

${ }^{8}$ Provisões, alvarás e sesmarias. Rio de Janeiro, Tipografia Monroe, p.170, 348-349.1930(Documentos Históricos, série 16, Biblioteca Nacional. Vol. 18).

${ }^{9}$ GALVÃO. Mons.Renato de Andrade. Os povoadores da região de Feira de Santana. Manuscritos do Livro de memória da região de Feira de Santana. Museu Casa do Sertão. Universidade Estadual de Feira de Santana

${ }^{10}$ Transcrição do depoimento de Sr. Raul Ferreira da Cruz, em colaboração para o projeto de História Oral de Irará. 
Quando se instalou o negócio de meeiros, houve este intercâmbio entre os escravos e meeiros. Os antigos escravos ficaram conhecidos como meeiros, pois voltaram a trabalhar com os patrõesaqueles melhores. Outros negaram os patrões e foram embora, pra outro lado, trabalhar por conta própria... Tinha patrões que davam a meia naquela época pra tirar tudo do trabalhador. O sujeito fazia tudo, quer dizer: limpar, capinar, ciscar, tirar o cisco, botar adubo por conta dele, cavar e dividir depois de maduro, a mandioca ou o fumo...

O meeiro era visto como um semi-escravo, o agregado, o camponês altamente dependente e dominado pelo grande coronel - o latifundiário continuava a ser o melhor perfil da sociedade brasileira. Podem também ser chamadas de lutas pelos direitos humanos as revoltas populares contra vários tipos de opressão por parte do Estado e das elites dominantes, em cada época histórica. Entram nesse rol as iniciativas de resistência dos índios e dos negros. Pois, sendo a eles proibido, inclusive, o direito de recurso da terra, passaram a negar papéis antes inerentes à escravidão, como receber rações diárias, ir ao trabalho nos canaviais ou trabalhar sem remuneração.

Era muito freqüente a figura do agregado, morador ou lavrador que morava com a família na fazenda do patrão, em pequeno terreno cedido para fazer uma roça para sua sobrevivência. Sem dúvida, essa peculiar característica de fronteira em que o indivíduo tem a possibilidade de emancipação, principalmente se engajado em milícias ou trabalhando na pecuária, é um fato singular e que merece estudos. Contudo, é limitado a um específico período, e mais, um determinado contex to beligerante. Esses sujeitos eram completamente dependentes dos senhores donos de terras. Por conta dessa dependência, os fazendeiros exigiam parte da produção dessas roças pelo uso de suas terras. Em troca do trato de terra e da proteção que recebia do proprietário da terra, os trabalhadores deviam a este a contraprestação de serviços não-econômicos. Eles constituíam uma clientela política, ou seja, eram eleitores de cabresto, e serviam como guardiães da propriedade. Esses homens, pobres viviam como agregados, parceiros, meeiros, ou como morador de um pequeno sitio, conquistado através da prática de arrendamento, ou foreiro. Para sobreviver em paz, os roceiros viviam comandados pelos caprichos e interesses do grande proprietário que monopolizava o acesso à terra.

Conforme Erivaldo Fagundes Neves (1998), "a escravidão desenvolveu-se no sertão baiano, simultânea e articuladamente com a meação, confundindo choupanas de agregados e casebres de escravos." Daí vêm as histórias dos agregados feitos eleitores, jagunços, defensores de divisas de terras, 
ganhando sentido a partir da humildade dos serviços que prestavam. Dessa forma, muitos ex-escravos passaram a procurar esses serviços, já que não existia um controle jurídico em torno do trabalho do pequeno lavrador. Diversos ex-escravos e mestiços livres compravam e arrendavam terras, em virtude da inexistência de lei que os autorizava a comprar terras, assim como executarem o arrendamento das mesmas ${ }^{11}$. No processo de arrendamento, os fazendeiros apenas exigiam parte da produção dessas roças pelo uso de suas terras. Esta natureza das condições do trabalho tornava mais nítida a importância dos lotes de lavouras. O plantio permitia a reprodução do trabalho familiar ${ }^{12}$. Os membros da família trabalhavam para o patrão recebendo ou não a diária e nos dias "livres" trabalhavam por conta própria. Além disso, também era freqüente a modalidade das roças arrendadas por uma quantia ou por um contrato de meia, ou de terça e até de quinta parte da produção. Esse sistema de meia era comum entre os pequenos lavradores que não tinham condições para comprar a semente e outros insumos. Nas lavouras de mandioca, feijão, milho e fumo aparece um tipo de contrato de sociedade: o proprietário limpava e preparava o terreno e o lavrador plantava e cultivava, sendo depois a produção dividida ao meio.

Mesmo após a abolição, muitos negros permaneceram nas fazendas, trabalhando sem nada receber. O que se percebe é que o trabalho livre aparece como complementar ao escravo. Os fazendeiros, para quitarem suas dívidas com os ex-escravos, "doaram-lhes" pedaços de terra improdutivos, mais altos, sem trato e distantes da água. Esses ex-escravos ali permaneceram e casaram entre si, aumentando a população local. Neste caso, as pessoas assumiam o trabalho de meia como uma nova relação com o senhor. Já que não aceitaram continuar nas antigas fazendas, foram morar em comunidade livres.

Pode-se considerar que a formação das comunidades quilombolas de Irará tem sua possível origem ao longo dos séculos XVIII e XIX, nos processos de resistências organizados pelos escravos através da formação de famílias. Sob a tutela da família, o negro encontrava vínculos de solidariedades capazes de resistir à pressão do cativeiro, e até mesmo negociar a liberdade com os senhores. Muitos escravos passaram a comprar cartas de alforrias, através dessas relações que foram estabelecidas. Muitos deles viviam em pequenos grupos itinerantes, não tinham acampamentos fixos, e suas economias se caracterizavam, de maneira geral, por um caráter extrativo e predatório. Estes grupos de escravos não reivindicavam a destruição definitiva e imediata da escravidão, e sim, uma forma negociada (melhores condições) de conviver entre: senhores, africanos, mulatos e crioulos. Entretanto, outros grupos de escravos aventuravam-se pelas áreas florestais em busca de terras para trabalhar.

\footnotetext{
"GALVÃO. Mons. Renato de Andrade. Os povoadores da região de Feira de Santana. Manuscritos do Livro de memória da região de Feira de Santana. Museu Casa do Sertão. Universidade Estadual de Feira de Santana.

${ }^{12}$ Idem.
} 
Assim, essa região passou a ser vista pelo ex-escravo como um lugar em que a liberdade poderia se estabelecer, por meio da posse da terra. A liberdade viria com o acesso à terra, o direito de escolher onde trabalhar e o direito de circular livremente pelas cidades, sem a necessidade de pedir autorização a outrem; enfim, o que se almejava era o direito de cidadania.

Depois que as famílias tomavam posse das terras, formavam-se os agrupamentos através dos laços de parentesco. Essas pessoas viviam através do uso comum das terras, onde praticavam a agricultura baseada na mão-de-obra familiar. As localidades eram herdadas em linha agnática, assegurando aos parentes lineares o controle sobre o território. As residências se estabeleciam em determinado setor tendo por foco aglutinador as parentelas agnáticas de parentes mais próximos, os quais se constituíam da unidade social de maior densidade, a comunidade em si. $O$ trabalho era feito coletivamente ${ }^{13}$ :

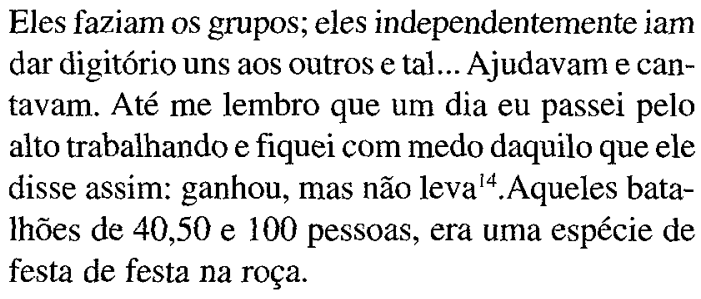

Dessa forma, muitos ex-escravos passaram a afirmar sua liberdade negando trabalho, às propriedades dos senhores brancos. A literatura que trata da transição da mão - de - obra escrava para o trabalho livre, destaca que muitos pretos e crioulos estavam sempre sujeitos à reescravização, já que nem sempre possuíam prova de sua liberdade. Assim sendo, algumas comunidades de afrodescendentes livres eram rotineiramente combatidas.

Esses grupos resistiam mediante à criação de laços de solidariedade que eram estabelecidos através do uso comum dos recursos naturais de forma harmônica: consumiam, produziam e comercializam o excedente adquirido na própria terra. Esses indivíduos comercializavam produtos alimentícios produzidos em pequenas extensões de terra, como: feijão-de-corda, mangalô, andu, licuri, entre outros. Também comercializavam produtos artesanais, como: cordas, chapéu de palha, balaios, potes e panelas de barro. Entre os quilombolas da comunidade da Olaria, a produção de cerâmica demarca a trajetória dos grupos. Lá, os sujeitos encontraram a produção de objetos de cerâmicas, principalmente telhas e tijolos, para resistirem ao processo de dominação dos senhores brancos: os homens faziam as telhas e os tijolos, as mulheres fabricavam potes, panelas e pratos.

\footnotetext{
13 Idem.

14 Idem.
} 
Toda essa produção era vendida nas feiras livres da região: em Feira de Santana, Irará e Nazaré das Farinhas. Os homens escoavam a produção a partir do transporte de animais de cargas, eram as tropas de burros. Alguns narram que esses tropeiros, além de se encarregarem de escoar a fabricação local, também traziam "novidades" do comércio, como produtos alimentícios a vestuário. As famílias livres - que não viviam sobre a tutela dos senhores formavam agregados eventuais (filhos adotivos, "primos", ou "tios"), centrados (e organizado) na figura de um chefe - o pai ou (com a morte deste) o irmão mais velho.

Depois de estabelecidos, na comunidade quilombola, os membros deste grupo mantiveram uma integração entre se e conflitos com os outros, ou seja, os que não faziam parte da comunidade. Nessa perspectiva, a etnicidade revela-se nas ações e reações entre o grupo e os outros em uma organização social que não deixa de evoluir. Esses conjuntos de componentes sociais que são mutáveis variaram de acordo com o tempo e, nesse incessante processo de mudanças sociais, políticas e culturais. (Poutignat e Fenart, 1998: 188). Ao discorrer sobre essas incidências, organizou-se uma abordagem que conjetura considerações sobre a representação da etnicidade, através da proeminência das relações de fricção interétnicas ${ }^{15}$.

\section{Considerações finais}

Os habitantes dessa região vislumbram que esse trabalho possa resultar numa perspectiva de engajamento na luta por sua libertação coletiva. Esse movimento social local emergiu na região pesquisada, especialmente através da articulação de jovens católicos e representantes da associação dos moradores. Esse público letrado aprofundou-se na discussão sobre os quilombos através de informações que são veiculadas pela mídia, especialmente a televisão, que divulgou durante os últimos dias o reconhecimento de comunidades quilombolas, por meio da titulação conferida pela Fundação Palmares.

Por meio dessa investigação, percebeu-se que já existem os movimentos sociais alternativos que emergem em comunidades negras rurais. As pessoas que moram nas comunidades negras da Serra de Irará sentem-se excluídas no entorno regional e, por conta disso, querem rever a história de sua comunidade. Como diz Sivanilda Jesus Puscena ${ }^{16}$ :

\footnotetext{
${ }^{15} \mathrm{O}$ conceito de fricção interétnica é muito usado para tratar da questão indígena no processo da construção da sociedade nacional. A idéia de fricção configura-se a idéia de atrito entre etnias diferentes e culturas diferentes. Esse processo é um demonstrativo das práticas, dos conflitos e junções que, ora são vistos como negativos e ora são vistos como positivos. DE OLIVEIRA, R.C. A Sociologia do Brasil Indígena. Brasília e RJ:Editora da UnB e Tempo Brasileiro, 1978. Ver os capítulos V ("O Índio na Consciência Nacional", pp. 65-74), VII ("Problemas e Hipóteses Relativos à Fricção Interétnica", pp. 83-98). BCE Reserva, 39 (81:082) O48s.

${ }^{16}$ Sivanilda Jesus Puscena, lavradora, mãe de dois filhos, nascida em 03/12/85, residente na Olaria.
} 
O povo tem vergonha de ser da Olaria, porque as outras pessoas ficam falando que a gente é bagunceira. Quando a gente passa lá no Murici, o povo já fala assim: "Lá vem os pisa barro da Olaria. Por isso muita gente tem vergonha de ser da Olaria. É porque tem vergonha de ser nego também. As outras pessoas falam que aqui no Olaria só tem nego. Por conta disso todo mundo tem vergonha. Mas, quando eu entro no ônibus da escola e o povo fala: já vem o povo da Olaria... "eu logo digo: sou da Olaria mesmo! E daí? Não tenho vergonha de ser de lá...

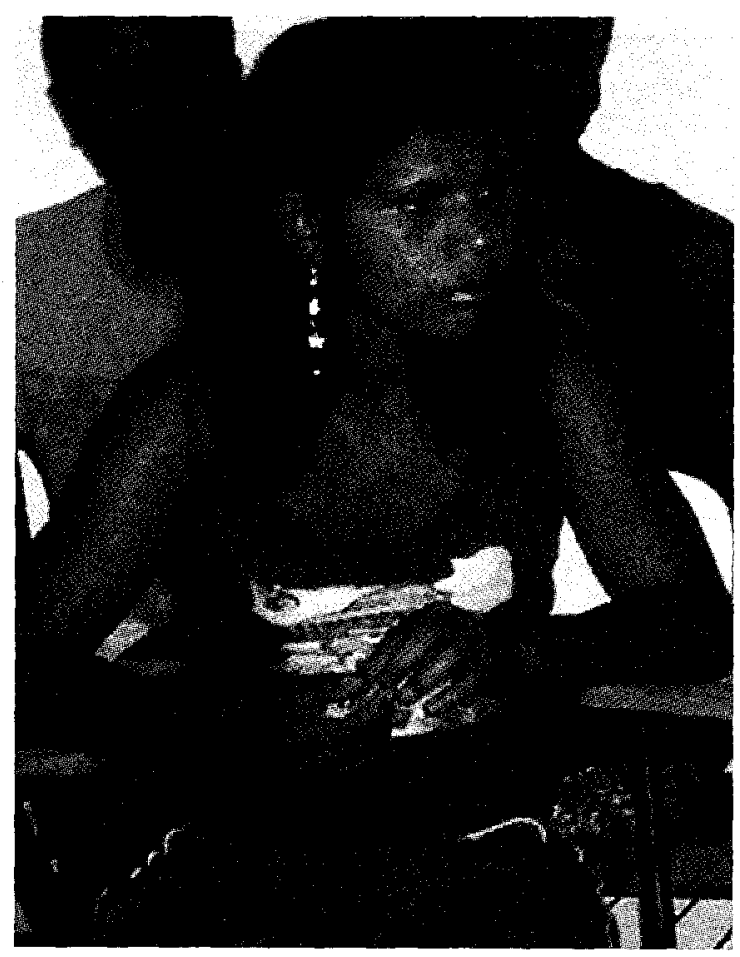

Figura 2

Sivanilda Jesus Puscena

Apesar de serem discriminados, os sujeitos que moram na região pesquisada mantêm uma organização social que faz com que fortaleçam a sua identidade, através da manutenção de um conjunto de signos que os distinguem como um grupo diferenciado. A fidelidade às origens é mantida através da afirmação do parentesco. Contudo, essas pessoas afirmam em seus discursos que elas são diferenciadas dos outros, na região, por conta de seu perfil racial e de pobreza. 


\section{História da comunidade quilombola de Olaria (Irará/Bahia)...}

O depoimento de Sivanilda é repleto de elementos que falam do perfil da identidade do grupo, quais seguem os aspectos culturais que fazem com que as pessoas se sintam parte da comunidade, identificando-as como grupo e as diferenciando-as dos outros. O perfil da etnicidade do grupo aparece no seguintes elementos: fator étnico-racial, condição econômica, e trabalho de produção de cerâmica. Segundo Barth (1998), "um grupo étnico é um grupo de pessoas que se identificam umas com as outras, ou são identificadas como tal por terceiros, com base em semelhanças culturais ou biológicas, ou ambas, reais ou presumidas". Dessa forma, a organização social da região pesquisada engloba uma clássica característica da atribuição étnica, ou da identidade étnica, por ser categorizada por si mesmo e pelos outros; um tipo de organização baseada na auto-atribuição dos indivíduos às categorias étnicas. Quando a jovem diz: "sou da Olaria mesmo! E daí?" Ou quando enfoca aquilo que é socialmente efetivo, os grupos étnicos, deixa clara, a atribuição de uma identidade ou "categoria étnica" determinada por uma origem comum presumida e destinos compartilhados, afirmando o sentimento de grupo. Nesse exemplo, os processos de identificação étnica não derivam, apenas, da psicologia dos indivíduos, mas da constituição de espaços de visibilidade e das formas de interação com o "mundo externo. ${ }^{17}$

Para Barth (1998), cada grupo compartilharia "uma cultura comum e diferenças interligadas que distinguiriam cada uma dessas culturas tomadas separadamente de todas as outras". Nesse caso, a etnicidade aparece nos processos sociais de exclusão ou incorporação de elementos propiciadores de significados simbólicos (uma identidade), tanto em níveis coletivos como individuais. Assim, as pessoas conseguem assegurar uma unidade grupal, porque a comunidade possui caráter organizacional.

A "solidariedade étnica" manifesta-se no confronto com elementos estrangeiros, como oposição ou desprezo pelo que é diferente, despertando neste embate entre o "nós" e os "outros" o sentido de unidade grupal ${ }^{18}$. Dessa forma, as pessoas se organizam em prol da coletividade, na qual se desenvolvem ajudas mútuas.

Hoje, essas pessoas estão vivendo um processo de construção identitária: elas têm consciência que de descendem diretamente de ex-escravos africanos, e sua característica comum está ligada ao "desenvolvimento de práticas de resistência na manutenção e reprodução de seus modos de vida". Conforme voz corrente na comunidade, as terras que são habitadas pelos nativos foram doadas pelos ancestrais. Essa história tem iníco no momento em que colonizadores e colonizados firmaram as bases iniciais dos seus relacionamentos na sociedade local.

17 POUTIGNAT, P. \& STREIFF-FENART, J. Teorias da etnicidade, seguido de Grupos étnicos e suas fronteiras, de Fredrik Barth. São Paulo: Editora da Unesp, 1998.

18 WEBER, M. Relações comunitárias étnicas. In: Economia e Sociedade: fundamentos da sociologia compreensiva. Brasília: Editora da UnB, 1994 [1922]. 
Em decorrência disso, a comunidade da Olaria acabou por ocupar no sistema finalmente estabelecido, em se tratando da sua situação física, geográfica e cultural, um lugar muito além das formas pelas quais a comunidade é integrada ao entorno regional. Dessa forma, os nativos almejam relacionar a memória da escravidão e da resistência com a atual discussão sobre o conceito de quilombos. Através dessas atividades, as pessoas que ali residem, planejam executar um trabalho respaldado na memória dos mais velhos, em que últimos passarão a fazer um retorno àquele passado fincado na escravidão e a lembranças pouco ou nada prazerosas que costumam se apagar da memória.

$\mathrm{O}$ alvo inicial desse povo é a conquista da titulação das terras das comunidades e a construção de um perfil de identidade quilombola que se firme politicamente, posto que a legislação brasileira já adota este conceito de comunidade quilombola e reconhece que a determinação da condição quilombola advém da auto-identificação. $\mathrm{O}$ auto-reconhecimento garantido no Decreto $\mathrm{n}^{\circ}$ 3.572 , de 22 de julho de 1999 só foi estabelecido na legislação federal em novembro de 2003 , através do Decreto $n^{\circ} 4.887$. Depois da aproximação dos sujeitos, através dos encontros promovidos na associação local, notou-se o quanto essas pessoas estão ávidas por entenderem o significado da palavra quilombos, a fim de mudarem a sua comunidade. De acordo com o seguinte depoimento percebe-se ${ }^{19}$ :

A gente quer saber por que agora tá dizendo que aqui é um quilombo. Antes o povo mais velho falava da escravidão e dessa história que os negros se escondiam no mato. Mas, agora a gente quer saber por que as pessoas se interessaram para dizer que aqui é um quilombo. Eu ouvi na televisão que o quilombola tem direito a vaga na universidade. Eu quero saber como a gente pode ter vaga para estudar na universidade, porque ainda eu sonho em continuar com meus estudos. Além disso, tem outras coisas que sempre aparece na televisão, mas a gente não entende bem o que passa na televisão. A gente quer saber como nós é visto como quilombola e que a gente pode ganhar com isso...

Foi possível perceber que esses sujeitos já não querem mais assumir uma postura passiva diante da sua trajetória coletiva. As pessoas que moram nessas comunidades sonham com a transformação do lugar. Dentre as principais questões que as pessoas almejam, aparecem as seguintes: melhoria e/ou implantação dos serviços de saúde com qualidade nas comunidades;

${ }^{19}$ Elza dos Santos, moradora da Olaria, nascida em 30/01/1982. 
implantação do Programa Saúde da Família nas comunidades; implementação de ações efetivas de detecção e controle da anemia falciforme nas comunidades; atendimento odontológico; cursos que promovam o desenvolvimento das potencialidades dos jovens das comunidades nas áreas de educação e de qualificação profissional; realização de cursos de alfabetização para jovens e adultos; melhor estruturação da escola existente na comunidade com suporte de materiais pedagógicos; reforma e ampliação da escola que existe na região (Escola Municipal Ana Souza Carneiro); transporte escolar com qualidade e segurança para os jovens que estudam fora da comunidade; revitalização do trabalho com a cerâmica; e demarcação das terras que pertenceram aos ancestrais.

Hoje, os sujeitos que moram na comunidade quilombola da Olaria querem recuperar da história desses grupos, a fim de fomentarem a luta por terras. Portanto, tornou-se interessante a aproximação dos sujeitos pesquisados para, juntos pensarem no contexto das desigualdades e exploração coletiva. Uma vez que nesses espaços os indivíduos já nascem com papéis definidos- uns nascem para mandar e outros para obedecer, uns oprimem e outros são oprimidos- a prática da pesquisa pode ser um meio de promover a transformação social em busca da igualdade e da valorização do ser humano. Portanto, a pesquisa que articula a metodologia descolonial não pode exercer um papel imparcial, mas sim criar um espaço para discussão e luta pela mudança. Assim, a pesquisa aproximou-se de uma prática que objetivou a libertação dos aparatos de dominação constituídos a partir do colonialismo, o qual tirou o direito de ser dos negros, como os quilombolas.

\section{Referências bibliográficas}

ABA. 1994. Documentos do Grupo de Trabalho sobre as comunidades Negras Rurais. Em Boletim Informativo NUER, n.l.

ABREU, J. C. 1930. Caminhos antigos e povoamento do Brasil. Sociedade Capistrano de Abreu. Rio de Janeiro.

ALMEIDA, A. W. Terras de preto, terras de santo, terras de índio - uso comum e conflito. In: Na trilha dos grandes projetos - modernização e conflito na Amazônia. Org. Edna M. R. de Castro, Jean Hébette. Belém: NAEA/ UFPA, 1989.

ALMEIDA, A.W. Quilombos: sematologia face as novas identidades. In: Frechal: Terra de preto - quilombo reconhecido como Reserva Extrativista. São Luís: SMDDH/CCN-PVN, 1996. 
ALMEIDA, A.W. .Os quilombos e as novas etnias. In: LEITÃO (org.) Direitos Territoriais das comunidades negras rurais. São Paulo: Instituto Socioambiental, 1999.

ANDRADE, Lúcia e TRECCANI, Girolamo. Terras de quilombo. São Paulo. mimeo., p.21.

ANJOS, R. S. A. Territórios das comunidades remanescentes de antigos quilombos no Brasil-primeira configuração espacial, edição do autor, Brasília, 1999.

CARRIL, L. F. B. Quilombo, favela e periferia: a longa busca da cidadania 2003, Tese (doutorado em geografia) USP, São Paulo.

ARRUTI, J. M. Mocambo: Antropologia e história do processo de formação quilombola. Bauru- São Paulo Edusc, 2006.

ARRUTI, J.M. Recuperação da memória do lugar auxilia laudo antropológico. Entrevista concedida em 10/03/2004. Disponível em $<$ www.comciência.br>.

BENTES. Enciclopédia de Bíblia, teologia e filosofia. São Paulo, Candeia, 1995.

BARTH, F. Os grupos étnicos e suas fronteiras. Em P. Poutignat \& J. StreiffFenart (orgs.). Teorias da identidade. São Paulo, UNESP, 1998. p. 185-227.

BIBLIOTECA NACIONAL (BRASIL). Documentos históricos [Tombo das Cartas de Sesmarias do Rio de Janeiro dadas por Cristóvão de Barros (157374) dadas por Salvador Correia de Sá (1578-79)] / Biblioteca Nacional. Vol. 1. Rio de Janeiro: Fundação Biblioteca Nacional, Dep. Nacional do Livro, 1928.

BRASIL. Constituição da Republica Federativa do Brasil. Brasília: Senado, 1988.

BRASIL. Decreto Presidencial 4.887/2003 de 20 de novembro de 2003. In: Diário oficial da União Édição Número 227 de 21/11/2003.

BOURDIEU, P. (1980a). Le Nord e Le Midi: Contribution a une analyse de l'effet Montesquieu, in Actes de la recherche en Sciences Sociales, 65 novembre.

CARDOSO DE OLIVEIRA, R. A Sociologia do Brasil Indígena. Brasília:UnB; R.J.: Tempo Brasileiro, 1978.

CARNEIRO, E: O quilombo dos Palmares. São Paulo: Cia. Editora Nacional, 1958. 


\section{História da comunidade quilombola de Olaria (Irará/Bahia)...}

CASHMORE, E. Dicionário de relações étnicas e raciais. São Paulo: Summus, 2000.

CARVALHO, J. J. Prefácio. In CARVALHO, José Jorge (Org) O quilombo do Rio das Rãs. Histórias, Tradições, Lutas. Salvador, EDUFBA, 1996 p. 7-10.

COHEN, A. The symbolic construction of community. Londres: Routledge, 1985.

FAORO, R. Os donos do poder. 10 ed. Globo; Publifolha, vol.1 (Cap. 1 e 3, p. 3-34 e p. 83-109), São Paulo, 2000.

FRAGA, W. F. Encruzilhadas da Liberdade. Campinas: Editora da Unicamp, 2006.

GALVÃO. R. A. Os povoadores da região de Feira de Santana. Manuscritos do livro de memória da região de Feira de Santana. Museu Casa do Sertão. Universidade Estadual de Feira de Santana.

GOMES, F. S. Quilombos do Rio de Janeiro do Século XIX. In: REIS, J. J. \& GOMES, F. S. (orgs.): Liberdade por um fio. História dos quilombos no Brasil. São Paulo: Cia. das Letras, 1996.

POUTIGNAT, P. \& STREIFF-FENART, J. Teorias da etnicidade. São Paulo: UNESP, 1997.

MATTOSO, K. Q. Ser escravo no Brasil. 3. ed. Sao Paulo: Brasiliense, 1990.

MIRADOR. 1980. Dicionário brasileiro da Lingua Portuguesa. São Paulo: Enciclopédia Britânica do Brasil/ Companhia Melhoramentos de São Paulo.

NEVES, E. F. Da sesmaria ao minifúndio (um estudo de história regional e local). Salvador: Editora da Universidade Federal da Bahia; Feira de Santana: Universidade Estadual de Feira de Santana, 1998.

POUTIGNAT, P. \& STREIFF-FENART, J. Teorias da etnicidade, seguido de Grupos étnicos e suas fronteiras, de Fredrik Barth. São Paulo: Editora da Unesp, 1998.

PORTO, C. O sistema sesmarial no Brasil. Ed. Universidade de Brasília.

PROVISÕES, ALVARÁS E SESMARIAS. Rio de Janeiro, Tipografia Monroe, p.170, 348-349.1930(Documentos Históricos, série 16, Biblioteca Nacional. Vol. 18).

RAMOS, A. O negro na civilização brasileira. Casa do Estudante Brasileiro, Rio de Janeiro. 1953. 
REIS, J. J. \& GOMES, F. S. (org.). Liberdade por um fio. História dos quilombos no Brasil. São Paulo, Companhia das Letras, 1996.

TRANSCRIÇÃO DO DEPOIMENTO DE SR. RAUL FERREIRA DA CRUZ, em colaboração para o projeto de História Oral de Irará. Disponível em: <www.ibge.gov.br/estadosat/>.

WEBER, Max. cap. VII: Classe, estamento, partido. In Ensaios de Sociologia (edit. por H. H. Gerth e C. W. Mills). 5a. ed. Rio de Janeiro, ed. Guanabara, 1982. p. 211-228.

WEBER, Max. "Relações comunitárias étnicas". In: Economia e sociedade: fundamentos da sociologia compreensiva. Brasília: Editora da UnB, 1994 [1922]. 